\title{
Evaluasi Implementasi Masterplan Kawasan Agropolitan Ciwidey Menggunakan Logic Models
}

\section{Isnaeni Agustina ${ }^{1}$}

Departemen Perencanaan Wilayah dan Kota, Fakultas Teknik

Universitas Diponegoro, Semarang, Indonesia

\section{Artiningsih}

Departemen Perencanaan Wilayah dan Kota, Fakultas Teknik

Universitas Diponegoro, Semarang, Indonesia

Artikel Masuk : 22 November 2016

Artikel Diterima : 27 Januari 2017

Tersedia Online : 27 Maret 2017

\begin{abstract}
Abstrak: Pembangunan perdesaan perlu didorong untuk mengurangi kesenjangan kawasan perkotaan dan perdesaan, antara lain melalui program pengembangan kawasan agropolitan. Pemerintah Kabupaten Bandung telah menyusun Masterplan Kawasan Agropolitan Ciwidey pada tahun 2007, diimplementasikan tahun 2008-2012, dan dievaluasi tahun 2013-2016. Studi bertujuan untuk mengetahui kinerja dari rencana program dan kegiatan pengembangan kawasan agropolitan Ciwidey. Studi dilakukan menggunakan metode analisis logic models yang menjabarkan input, output, outcome, dan impact dalam suatu diagram yang kemudian diuraikan menggunakan deskripsi kausalitas. Hasil studi menunjukkan bahwa program pengembangan agropolitan berdampak positif bagi karakteristik fisik dan sosial, namun berdampak kurang baik bagi karakteristik ekonomi. Studi ini merekomendasikan bahwa diperlukan dukungan kelembagaan yang kuat dalam kegiatan agribisnis di kawasan agropolitan.
\end{abstract}

Kata kunci: agropolitan, evaluasi, logic models

Abstract: Rural development needs to be promoted for reducing inequalities in urban and rural areas through agropolitan development program, for example. The government of Bandung District has finished Ciwidey Agropolitan Masterplan in 2007, then implemented in 2008-2012, and evaluated in 2013-2016. This study aims to evaluate the performance of the program by using logic models to describe the input, output, outcome, and impact into a diagram and then described using causality description. The findings address that the program has positive impacts on physical and social characteristics, but it has adverse effects on the economic characteristics. This study recommends a robust support from the institutions required to developing the agropolitan area.

Keywords: agropolitan, evaluation, logic models

\footnotetext{
${ }^{1}$ Korespondensi Penulis: Departemen Perencanaan Wilayah dan Kota, Universitas Diponegoro, Semarang, Indonesia Email: isnaeni_agst@yahoo.com
} 


\section{Evaluasi Implementasi Masterplan Kawasan Agropolitan Ciwidey Menggunakan Logic Models}

\section{Pendahuluan}

Konsep agropolitan yang berkembang di Indonesia diadaptasi dari konsep agropolitan district yang dirumuskan oleh Friedmann dan Douglas pada tahun 1978. Secara harfiah, agropolitan berasal dari dua kata, yaitu agro yang berarti petanian dan metropolis yang berarti kota atau titik sentral dari berbagai kegiatan. Dengan demikian, agropolis atau agro-metropolis didefinisikan merupakan kota pertanian dan pengembangan kawasan agropolitan merupakan pengembangan berbagai aspek kehidupan untuk mendukung kawasan agropolis sebagai pusat pelayanan berbasis aktivitas ekonomi pertanian (Saefulhakim, 2004). Ini sejalan dengan pendapat Hoover (1977) bahwa kota merupakan pusat perkembangan dalam suatu wilayah dimana pusat kota tumbuh dan berkembang lebih pesat dibandingkan dengan daerah sekelilingnya sehingga agropolitan dapat didefinisikan sebagai pusat perkembangan pertanian dalam suatu wilayah yang didukung oleh daerah sekelilingnya sebagai hinterland. Lebih lanjut, Friedmann dan Douglas (dalam Lo \& Salih, 1978) mengungkapkan bahwa kawasan agropolitan merupakan suatu daerah pedesaan yang memiliki kepadatan penduduk sekurang-kurangnya 200 jiwa per $\mathrm{km}^{2}$. Setiap kawasan memiliki kepadatan penduduk 10.000 - 50.000 jiwa. Batas-batas district berdasarkan commuting radius (lingkar pulang-pergi) dengan jarak kurang lebih 5-10 km. Ukuran-ukuran tersebut menjadikan kawasan memiliki kepadatan penduduk rata-rata 50.000 - 150.000 jiwa.

Kawasan agropolitan merupakan wadah pengembangan sistem usaha agribisnis sehingga pengembangan agropolitan dan sistem usaha tani agribisnis saling terkait satu sama lain. Pengembangan agropolitan dapat memacu berkembangnya sistem dan usaha agribisnis serta tidak melupakan penyediaan kelengkapan fasilitas, sarana prasarana perkotaan dan diarahkan pada penyelenggaraan fungsi kota yang utama, yaitu pengadaan tempat tinggal, tempat bekerja, transportasi dan rekreasi. Hal ini sesuai dengan pendapat Prasetiya, Suyadi, Bisri, dan Soemarmo (2014) bahwa pengembangan kawasan agropolitan memerlukan integrasi antara sumber daya manusia dan sumber daya alam dengan meningkatkan nilai tambah dan sumber daya. Beberapa faktor yang menentukan pengembangan kawasan agropolitan, meliputi ketersediaan sumber daya alam, fasilitas, organisasi sosial masyarakat, dan ragam infrastruktur penunjang.

Secara skematik, kawasan agropolitan adalah kawasan terpilih sebagai pusat sistem pertanian dan pelayanan kegiatan pertanian untuk seluruh kawasan serta hinterlandnya (lihat Gambar 1). Menurut Soetomo (2002), distrik agropolitan merupakan unit urbanisasi pedesaan dengan kekuatan sumber perdesaan, yaitu pertanian, kerajinan, dan pariwisata. Distrik agropolitan dirancang agar kekuatan pembangunan bersumber dari sumber daya lokal dan stakeholder yang memiliki jalinan yang kuat.

Keterkaitan kota tani sentra produksi dengan hinterland atau dengan kota tani utama dihubungkan oleh beberapa tipe keterkaitan. Keterkaitan atau linkages dapat diartikan sebagai bentuk keterkaitan baik berupa aliran (flow) maupun interaksi (interaction) yang dapat terjadi antara desa dan kota. Serupa dengan Poli, Bisri, Surjono, dan Lengkong (2013) bahwa agropolitan merupakan kawasan pedesaan, hutan, dan kawasan pertanian kesatuan sistem yang saling terintegrasi dan terkoneksi melalui sistem jejaring. Sementara itu, tipe keterkaitan dua wilayah menurut Rondenelli (1985) dibedakan menurut bidang-bidangnya, meliputi a) tipe keterkaitan secara fisik yang mencakup jaringan transportasi dan ketergantungan ekologis; b) tipe keterkaitan ekonomi yang menyangkut pol-pola dasar, arus bahan baku, arus modal, pola konsumsi dan belanja, arus pendapatan, dan arus komoditi sektoral dan interregional; c) tipe keterkaitan pergerakan penduduk, meliputi migrasi temporer dan permanen serta perjalanan kerja; d) tipe keterkaitan teknologi yang mencakup ketergantungan teknologi, sistem irigasi, dan sistem telekomunikasi; e) tipe keterkaitan interaksi sosial yang mencakup pola visitting, pola kinship, kegiatan ritual dan keagamaan, dan interaksi sosial; f) tipe interaksi delivery pelayanan, meliputi arus dan jaringan energi, jaringan kredit dan finansial, pendidikan, training dan pengembangan, 
sistem delivery pelayanan kesehatan, pola pelayanan professional, komersial dan teknik, dan sistem pelayanan transportasi; serta g) tipe keterkaitan politik, administrasi dan organisasi, terdiri dari hubungan struktural, arus budget dan pemerintah, kebergantungan organisasi, pola otoritas oproval supervisi, pola transaksi inter-yuridiksi, dan rantai keputusan politik formal.

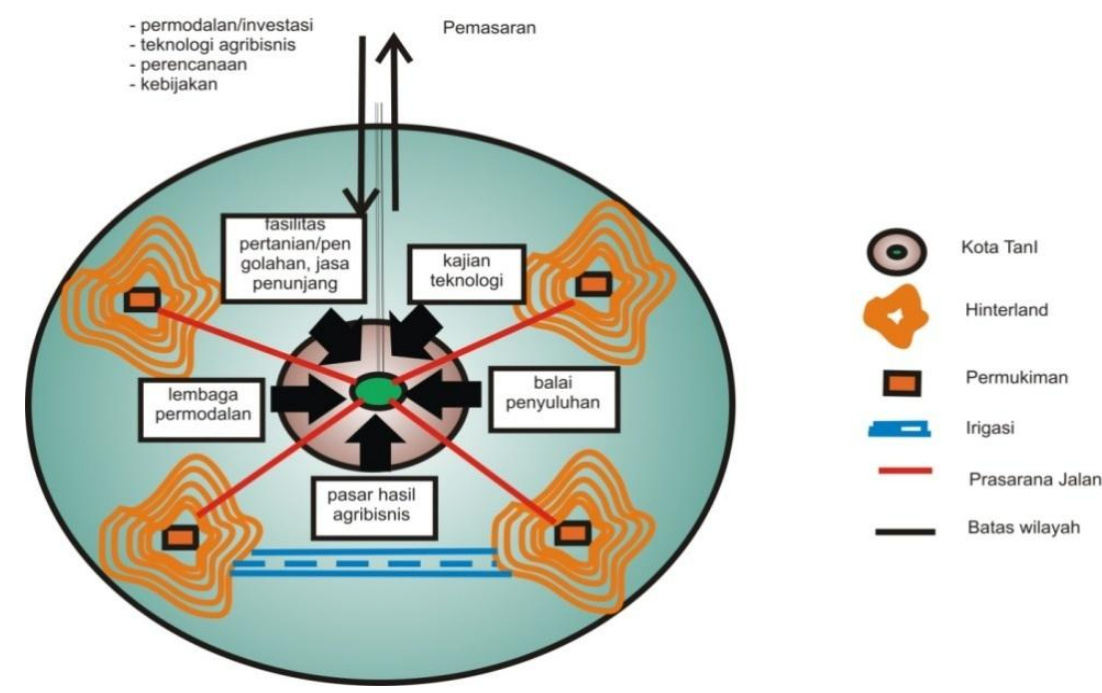

Sumber: Departemen Pertanian, 2002

\section{Gambar 1. Kawasan Agropolitan}

Agribisnis merupakan kegiatan yang berhubungan dengan penanganan komoditi pertanian, meliputi salah satu atau keseluruhan dari mata rantai produksi, pengolahan masukan dan keluaran produksi (agroindustri), pemasaran masukan-keluaran pertanian dan kelembagaan penunjang kegiatan. Kegiatan tersebut saling berhubungan yang bermakna bahwa kegiatan usaha yang menunjang kegiatan pertanian dan kegiatan usaha yang ditunjang oleh kegiatan pertanian. Downey and Erickson (dalam Saragih, 1998). Agribisnis termasuk sistem usaha tani yang meliputi pertanian tanaman pangan, hortikultura, perkebunan, kehutanan, peternakan dan perikanan serta bagian daripada sektor industri. Dalam sistem agribisnis, hasil produksi diolah agar terdiversivikasi sehingga nilai produk lebih tinggi daripada produk mentah. Dengan demikian, agribisnis dapat dilihat sebagai sistem pertanian modern yang memiliki komponen sub sistem berdasarkan kegiatan yaitu, subsistem sarana produksi atau upstream agribusness (hulu), subsistem budidaya atau onfarm, subsistem agribisnis hilir atau down stream agribusness, serta subsistem penunjang agribisnis (Saragih, 2007). Penyebutan hulu dan hilir mengacu pada pokok bahwa agribisnis bekerja pada rantai sektor pangan (food supply chain).

Pengembangan kawasan agropolitan di Indonesia didasarkan pada Undang-Undang No. 26 Tahun 2007 tentang Penataan Ruang dan didukung dengan keluarnya Peraturan Menteri Pertanian No. 50 Tahun 2012 tentang Pedoman Pengembangan Kawasan Pertanian. Pengembangan kawasan agropolitan dilaksanakan untuk meningkatkan pendapatan dan kesejahteraan masyarakat pedesaan melalui percepatan pengembangan wilayah dan peningkatan keterikatan desa dan kota. Hal tersebut dicapai dengan pengembangan sistem dan usaha agribisnis yang berdaya saing dan berbasis kerakyatan. Untuk itu, diperlukan kolaborasi antara pemerintah dan masyarakat lokal dalam langkah pengembangan agropolitan untuk memastikan bahwa program agropolitan berjalan baik 


\section{Evaluasi Implementasi Masterplan Kawasan Agropolitan Ciwidey Menggunakan Logic Models}

karena program agropolitan cukup kompleks terutama dalam perencanaan dan implementasinya (Shaffril, Nasir, Idris,Uli, \& D’Silva, 2010).

Penyusunan dokumen perencanaan kawasan agropolitan sudah dilakukan di beberapa daerah di Pulau Jawa termasuk Kabupaten Bandung. Pada tahun 2007 Pemerintah Kabupaten Bandung menyusun rencana pembangunan ekonomi daerah yaitu Masterplan Agropolitan Ciwidey. Menurut peraturan daerah Kabupaten Bandung tentang Rencana Induk Pariwisata Daerah (RIPPDA) Kawasan Ciwidey memiliki 7 desa yang ditetapkan sebagai wisata agro di Kabupaten Bandung, meliputi Desa Alamendah, Desa Ciwidey, Desa Pasirjambu, Desa Panundaan, Desa Sukawening, Desa Rawabogo, Desa Nengkelan. Agro wisata sebagai salah satu dampak dan tujuan pelaksanaan pengembangan Kawasan Agropolitan. Lingkup wilayah pengembangan Kawasan Agropolitan Ciwidey terdiri dari 3 kecamatan, yaitu Kecamatan Ciwidey, Pasirjambu, dan Rancabali (Gambar 1).

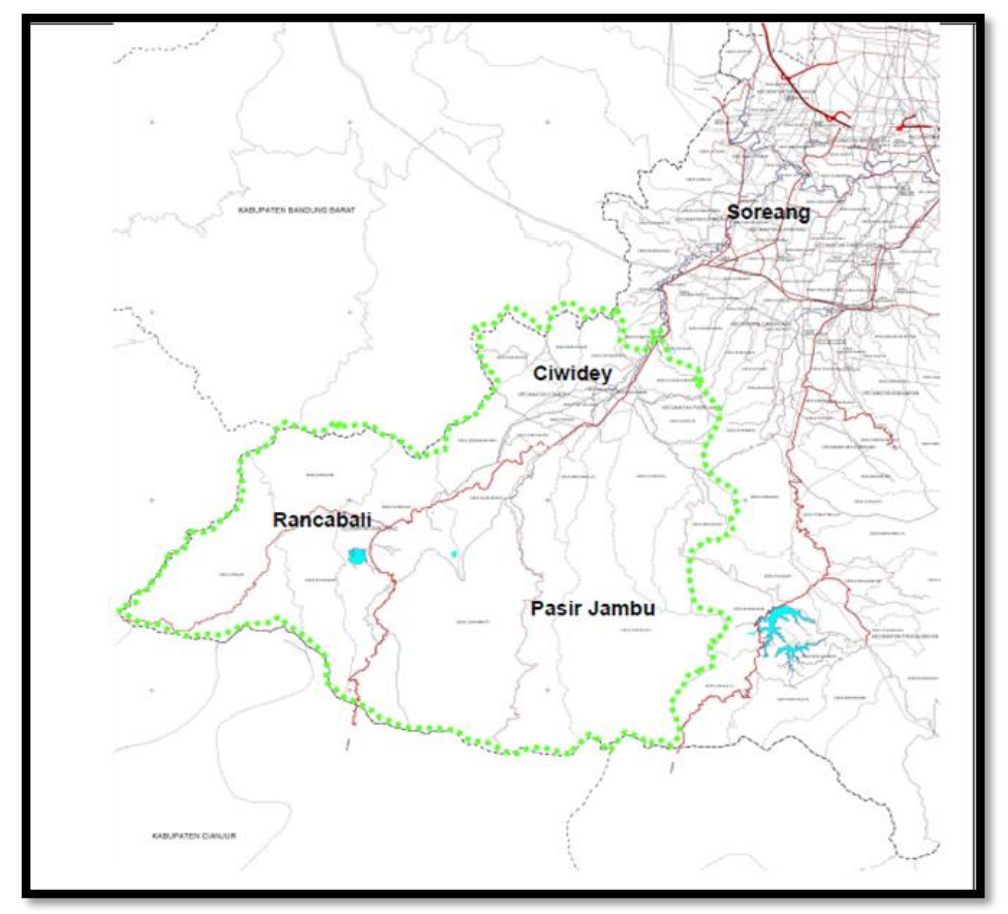

Sumber: Hasil Survey Badan Perencanaan Pembangunan Daerah Kabupaten Bandung, 2007

\section{Gambar 1. Kawasan Agropolitan Ciwidey}

Pengembangan kawasan agropolitan Ciwidey dilaksanakan sesuai dengan masterplan pembangunan kawasan agropolitan Ciwidey yang termasuk pada skala program pembangunan jangka menengah. Program pengembangan kawasan dilaksanakan dalam kurun waktu selama 5 tahun terhitung mulai tahun 2008-2012. Iqbal \& Anugrah (2009) mengungkapkan bahwa upaya monitoring dan evaluasi kegiatan dalam kebijakan agropolitan dan pengembangan ekonomi lokal diperlukan. Namun demikian, hasil penelitian Rosdiana \& Murwendah (2014) pada kawasan agropolitan di Kabupaten Bangli, Kabupaten Kuningan, dan Kota Batu menunjukkan bahwa kurangnya koordinasi dari pemerintah dalam implementasi program dan dukungan kebijakan keuangan menyebabkan upaya pengembangan agropolitan di ketiga wilayah tersebut kurang berhasil. Berbeda dengan kawasan agropolitan Ciwidey yang dikembangkan secara matang dan terkoordinasi. Studi ini bertujuan untuk mengetahui kinerja rencana program dan kegiatan pengembangan kawasan agropolitan Ciwidey. Hasil penelitian diharapkan dapat menjadi 
masukkan bagi pemerintah mengenai implemenasi rencana program pengembangan agropolitan yang sudah disusun berdampak pada penduduk Kawasan Ciwidey.

\section{Metode Penelitian}

Penelitian menggunakan metode penelitian kuantitatif dengan teknik analisis deskripsi kausalitas melalui pendekatan logic models. Logic models menurut McLaughlin \& Jordan (1999) merupakan salah satu alat evaluasi yang menceritakan proses kinerja program dengan menggunakan diagram. Diagram tersebut menyajikan keterkaitan antara input, kegiatan, output, target benefiary, dampak dalam jangka pendek, menengah, dan panjang. Model ini berguna agar evaluator menceritakan detail perkembangan dan kinerja program di lapangan. Gambar 2 merupakan contoh diagram logic models.

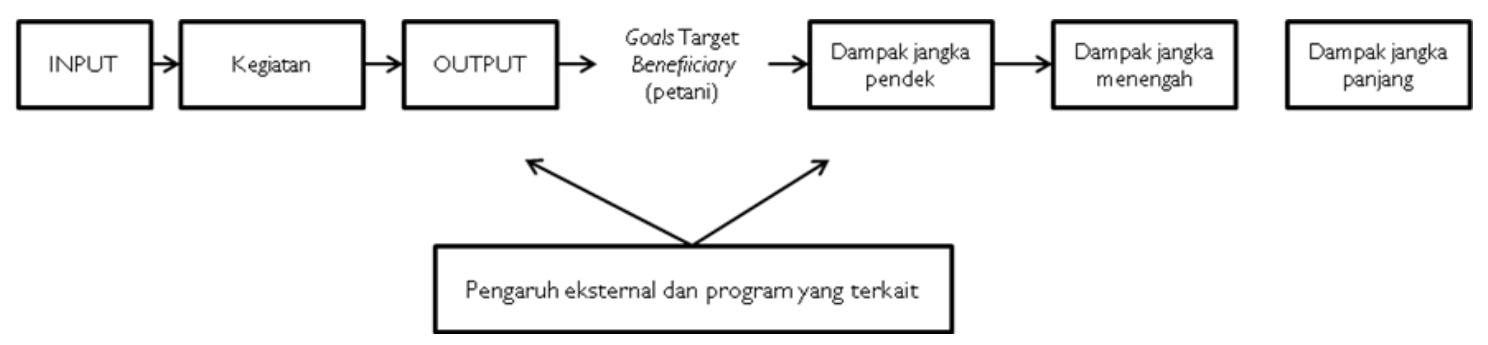

Sumber: McLaughlin dan Jordan, 1999

\section{Gambar 2. Diagram Logic Models}

Penggunaan logic models mempermudah evaluator untuk mengetahui apa saja yang terjadi selama input implelementasi kebijakan, pelaksanaan program kegiatan baik pada karakteristik fisik, ekonomi, dan sosial sehingga dapat diketahui hasil dari pembangunan yang telah terimplementasi, baik jangka pendek maupun jangka panjang. Penggunaan logic models juga dapat mengetahui masalah yang timbul pada saat pelaksanaan program kegiatan di lapangan. Namun, penggunaan logic models memerlukan data dan informasi yang mendalam tentang kegiatan yang dilaksanakan hingga diketahui hasil yang didapat.

Penggunaan logic models lebih efisien jika dilakukan oleh pemerintah Kabupaten Bandung sebagai pelaksana kebijakan Masterplan Kawasan Agropolitan Ciwidey. Metode pengumpulan data menggunakan metode kualitatif berupa teknik wawancara dan observasi lapangan. Hasil data yang diperoleh berupa deskripsi, fakta-fakta yang ada di lapangan.

Pendekatan logic models merupakan pendekatan yang menceritakan proses kinerja program dengan menggunakan diagram flow. Diagram tersebut menyajikan keterkaitan antara input, kegiatan atau proses berlangsungnya implementasi, output, outcome, dan impact. Proses logic models merupakan proses evaluasi dengan model yang masuk akal, meyakinkan hasil kinerja program dan untuk mengetahui bagaimana program kegiatan bekerja dibawah kondisi tertentu sehingga dapat mengidentifikasi masalah yang terjadi. Penerapan logic models pada implementasi Masterplan Agropolitan Ciwidey merupakan proses evaluasi dari kebijakan Masterplan Agropolitan Ciwidey. Input dari evaluasi ini adalah kebijakan Masterplan Kawasan Agropolitan Ciwidey itu sendiri, kemudian dikategorikan sesuai dengan karakteristik program kegiatan fisik, ekonomi dan sosial. Hal ini untuk mempermudah dalam membuat diagram logic models. Output merupakan hasil langsung yang terlihat dari kegiatan program Masterplan Agropolitan serta dampak jangka pendek dan panjang yang dirasakan oleh masyarakat. Logic models digunakan untuk menyelaraskan fungsi kebijakan Masterplan Agropolitan Ciwidey hingga implementasi 


\section{Evaluasi Implementasi Masterplan Kawasan Agropolitan Ciwidey Menggunakan Logic Models}

program dan hasil dari implementasi yang diharapkan sehingga kinerja dan perkembangan dari program kegiatan implementasi Masterplan Kawasan Agropolitan Ciwidey dapat diketahui melalui pendekatan ini.

\section{Hasil Pembahasan}

\section{Logic Models Karakteristik Fisik}

Penerapan logic models pada kegiatan program implementasi Masterplan Agropolitan Ciwidey menurut karakteristik fisik memiliki input kegiatan pada pembangunan fisik yang berfokus pada pembangunan infrastruktur dan sarana prasarana pendukung aktivitas pertanian dan agribisnis Kawasan Ciwidey. Peningkatan infrastruktur jalan perdesaan di kawasan agropolitan Ciwidey dicapai dengan adanya kegiatan perbaikan jalan utama, dan pembangunan beberapa titik jalan desa. Hal ini mendorong aksesibilitas kawasan agropolitan Ciwidey. Perbaikan infrastruktur irigasi juga dilakukan secara bertahap di kawasan agropolitan Ciwidey. Perbaikan pompanisasi pada komoditas sayuran, padi sawah dan strawberry. Irigasi kawasan agropolitan Ciwidey sudah berfungsi maksimal. Gambar 3 menunjukkan penerapan logic models menurut karakteristik fisik.

Pengadaan industri pengolahan dibangun untuk mendorong perkembangan agribisnis kawasan agropolitan Ciwidey terutama pada subagribisnis hilir (off-farm). Pengadaan sarana produksi pertanian kawasan agropolitan Ciwidey dilaksanakan untuk memberikan bantuan alat pertanian kepada petani yang memiliki jumlah dan jenis alat pertanian yang terbatas. Pengembangan pasar perdesaan dikelola oleh pemeritah daerah. Saat ini, kondisi Pasar Ciwidey masih dalam tahap perbaikan dan pembangunan beberapa fasilitas pasarnya. Hal tersebut dikarenakan faktor Pasar Ciwidey yang baru dibangun di tahun 2002. Kegiatan jual beli dan agribisnis di Pasar Ciwidey berjalan berdampingan, sehingga agribisnis kawasan agropolitan Ciwidey mulai berkembang.

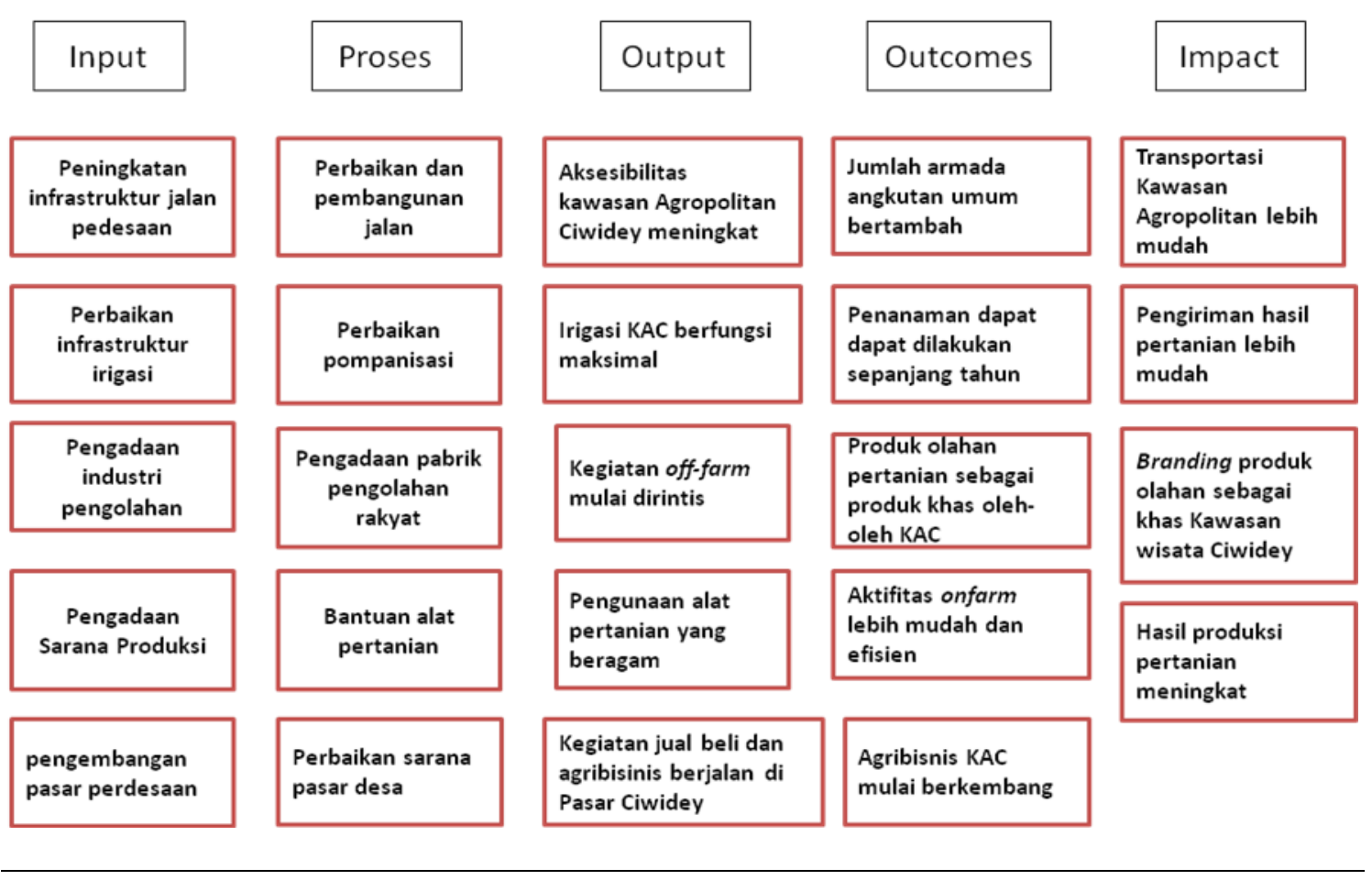

Gambar 3. Diagram Logic Models Karakteristik Fisik 
Dari diagram di Gambar 3 dapat diketahui peningkatan infrastruktur jalan pedesaan dan perbaikan infrastruktur irigasi memberikan impact langsung kepada masyarakat kawasan agropolitan Ciwidey. Manfaat lain yang dirasakan langsung oleh masyarakat adalah peningkatan aksesibilitas kawasan agropolitan Ciwidey dan penambahan armada angkutan umum sehingga memberikan kemudahan bagi transportasi di Kawasan Agropolitan dan pengiriman hasil pertanian. Di sisi lain, irigasi pada kawasan agropolitan Ciwidey mampu berfungsi maksimal sehingga penanaman dapat dilakukan sepanjang tahun dan hasil produksi pertanian meningkat. Input pengadaan industri pengolahan mendorong kegiatan off-farm dirintis dan hasil produksi menjadi produk khas oleh-oleh kawasan agropolitan Ciwidey. Perbaikan pasar pedesaan dengan memperbaiki sarana dan prasarana pasar desa sehingga kegiatan jual beli dan kegiatan agribisnis di Pasar Ciwidey berjalan lancar.

\section{Logic Models Karakteristik Ekonomi}

Diagram flow logic models karakteristik ekonomi memiliki input berupa goals atau tujuan dari kebijakan Masterplan Kawasan Agropolitan Ciwidey dalam membangun perekonomian Kawasan Agropolitan Ciwidey. Kebijakan tersebut antara lain dengan peningkatan nilai tambah produk, penguatan fasilitas akses permodalan, pengembangan produk unggulan desa dan pengembangan akses pemasaean produk desa. Gambar 4 menyajikan diagram logic models untuk karakteristik ekonomi. Dari diagram di Gambar 4 tersebut bahwa impact yang terjadi pada pembangunan ekonomi kawasan agropolitan Ciwidey adalah adanya petani padi sawah berpindah menanam komoditas sayuran sehingga mengakibatkan penurunan hasil produksi padi sawah.

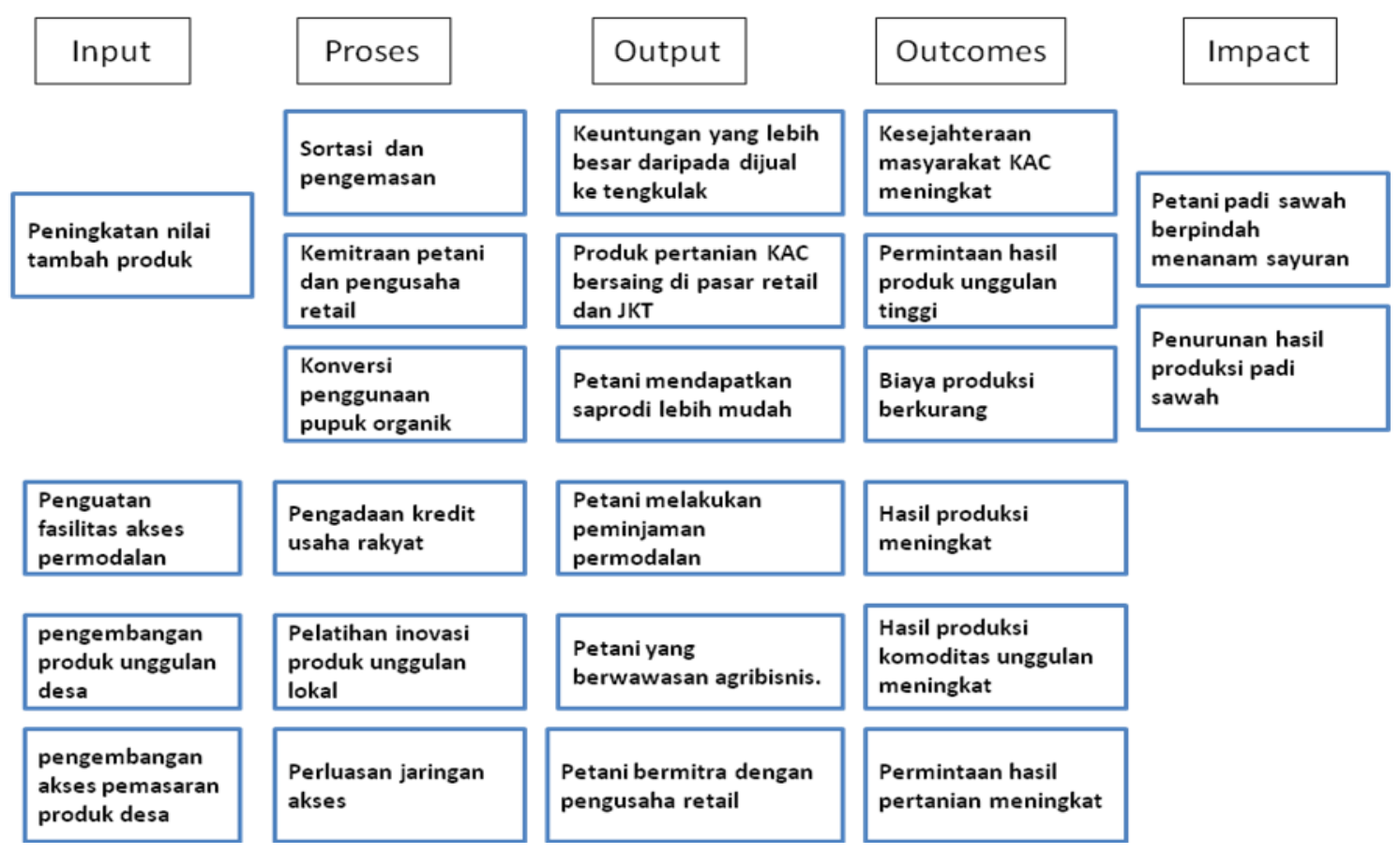

Gambar 4. Diagram Logic Models Karakteristik Ekonomi

Input kegiatan ekonomi Masterplan Agropolitan Ciwidey berfokus untuk meningkatkan kesejahteraan petani Kawasan Agropolitan Ciwidey. Penguatan fasilitas akses permodalan bagi petani yang kekurangan modal untuk bercocok tanam. Sementara 


\section{Evaluasi Implementasi Masterplan Kawasan Agropolitan Ciwidey Menggunakan Logic Models}

itu, pengembangan produk unggulan desa peningkatan nilai tambah produk dapat dilakukan dengan sortasi dan pengemasan. Input yang dilaksanakan pada pembangunan ekonomi memberikan kemudahan petani sayuran dalam menjual hasil pertanian. Petani kawasan agropolitan Ciwidey diperkenalkan dengan model kerjasama dengan pengusaha retail untuk dapat menjual produk pertaniannya yang berkualitas super bersaing di pasar retail Jakarta. Dengan adanya kemitraan dengan pengusaha retail, permintaan akan produk unggulan kualitas super tinggi. Hal tersebut memberikan peluang bagi petani sayuran dan membuat petani yang padi sawah berlomba menanam komoditas sayuran untuk mendapat keuntungan yang lebih besar.

\section{Logic Models Karakteristik Sosial}

Input kegiatan bidang sosial pada Masterplan Agropolitan Ciwidey adalah penguatan kelembagaan pertanian di kawasan agropolitan Ciwidey. Kelembagaan petani kawasan agropolitan Ciwidey mencakup koperasi usaha tani dan kelompok tani. Peran kelembagaan dalam usaha pertanian salah satunya dengan membantu petani mendapat informasi. Perbaikan teknologi budidaya selalu dilakukan karena teknologi pertanian dapat diperbaharui untuk mencari cara yang efisien dan memaksimalkan hasil produksi. Penyuluhan petani di kawasan agropolitan dilaksanakan jika ada kerjasama dengan pemerintah, seperti pada pengadaan demplot untuk komoditas teh dan kopi. Petani diberikan demonstrasi plot penanaman komoditas teh dan kopi. Gambar 5 memperlihatkan bahwa penguatan kelembagaan petani kawasan agropolitan Ciwidey diisi dengan diskusi dan studi banding antar petani tentang pengetahuan di bidang pertanian. Hal ini membuat petani bersemangat untuk terus belajar, menambah wawasan petani tentang agribisnis, serta mempererat hubungan antar petani. Pengembangan manajemen partisipatif masyarakat kawasan agropolitan Ciwidey dengan membentuk sistem dan mekanisme pola partisipatif masyarakat pedesaan.

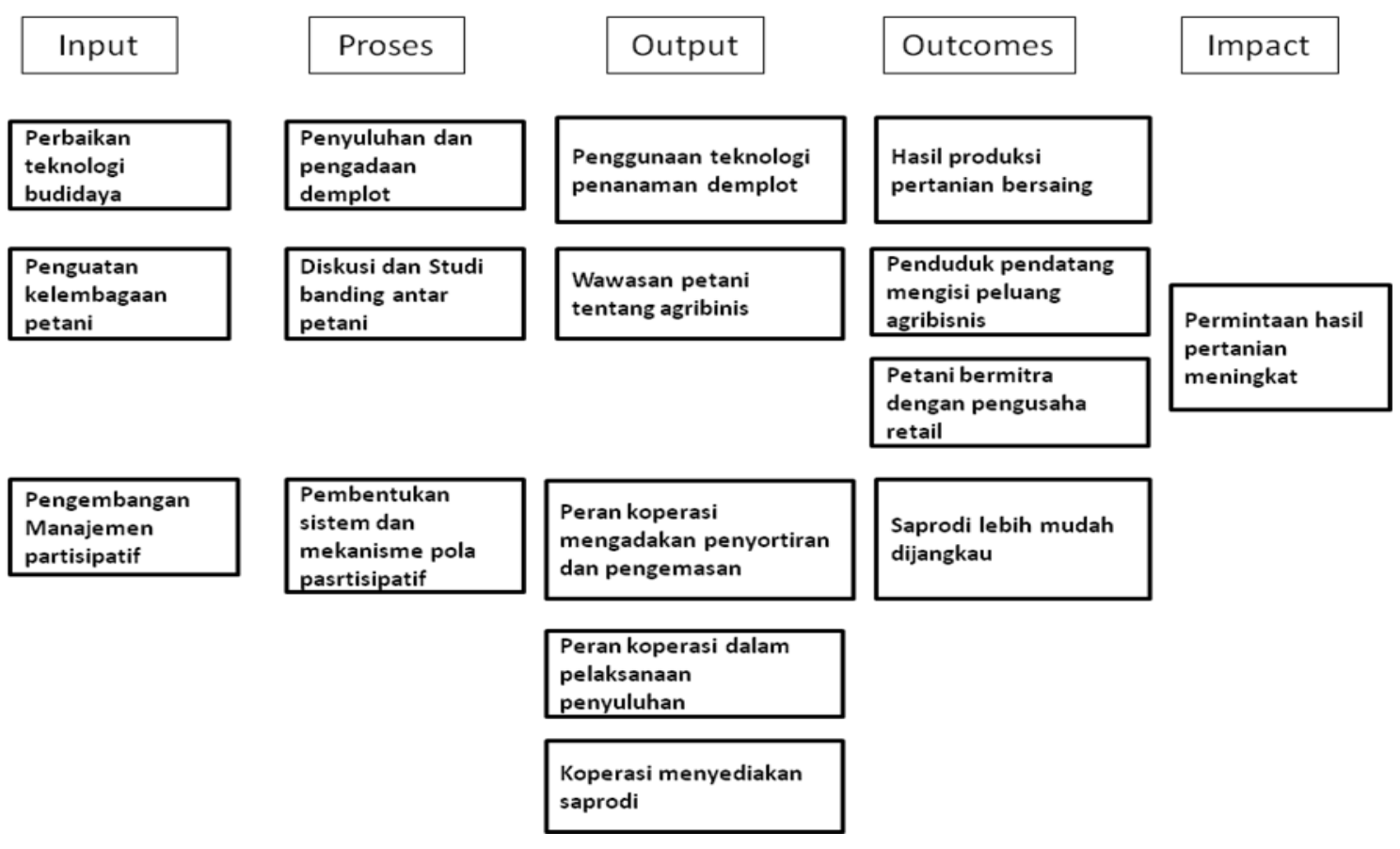

Gambar 5. Diagram Logic Models Karakteristik Sosial 
Penerapan metode logic models pada evaluasi implementasi Masterplan Kawasan Agropolitan Ciwidey memiliki kekurangan dan kelebihan masing-masing. Jika dibandingkan mengenai impact dari penerapan logic models karakteristik fisik, ekonomi, dan sosial, penerapan logic models pada karakteristik fisik dan sosial memiliki dampak positif bagi pengembangan kawasan agropolitan Ciwidey. Pada penerapan logic models karakteristik fisik yang meliputi peningkatan kualitas infrastruktur dan sarana, seperti prasarana jalan, irigasi, pengadaan sarana produksi, dan pengembangan pasar, mampu memberikan impact positif berupa kemudahan transportasi dan distribusi hasil pertanian. Begitu pula dengan penerapan logic models untuk karakteristik sosial bahwa perbaikan teknologi, penguatan kelembagaan petani, dan sistem manajemen juga berdampak positif bagi pengembangan agropolitan Ciwidey. Sementara itu, penerapan logic models untuk evaluasi karakteristik ekonomi menghasilkan dampak negatif bagi pengembangan agropolitan, seperti penurunan hasil produksi sawah. Ini dikarenakan adanya perluasan kemitraan dengan pengusaha retail menyebabkan munculnya peluang bagi petani sayuran untuk menanam sayur guna menghasilkan keuntungan yang lebih besar dan mengakibatkan penurunan hasil produksi padi sawah.

Jika dilihat secara keseluruhan, implementasi pengembangan kawasan agropolitan Ciwidey berdampak cukup baik bagi peningkatan kesejahteraan petani mengingat output yang dihasilkan adalah positif. Namun demikian, masih diperlukan upaya penguatan kemitraan antara petani dengan pengusaha, pembiayaan, dan perluasan akses jaringan dalam pengembangan produk unggulan desa. Hal ini sejalan dengan ungkapan Uphoff (1989) bahwa lembaga berperan penting dalam mendukung kegiatan agribisnis. Lebih lanjut, terkait upaya penguatan ekonomi, diperlukan upaya penguatan manajemen pengelolaan sumber daya dan pemanfaatan teknologi (Prasetiya, Suyadi, Bisri, \& Soemarmo, 2015). Serupa, Farhanah \& Prajanti (2015) juga berpendapat bahwa pengembangan sumber daya manusia dan teknologi, penguatan institusi, dan input produksi diperlukan untuk mengembangkan kawasan agropolitan.

\section{Kesimpulan}

Hasil evaluasi terhadap implementasi Masterplan Kawasan Agropolitan Ciwidey menggunakan metode logic models menunjukkan bahwa rencana program dan kegiatan pengembangan kawasan agropolitan Ciwidey memiliki dampak positif dan negatif. Hasil evaluasi untuk karakteristik fisik menunjukkan bahwa hasil pembangunan fisik Kawasan Ciwidey berdampak pada kemudahan transportasi dan pengiriman hasil pertanian, peningkatan hasil produksi pertanian, dan mampu memberi branding produk olahan pertanian sebagai oleh-oleh khas Kawasan Agropolitan Ciwidey. Untuk karakteristik sosial, pengembangan kawasan agropolitan Ciwidey berdampak pada peningkatan hasil pertanian karena terdapat penguatan kelembagaan petani melalui manajemen partisipatif. Namun, untuk karateristik ekonomi, pengembangan agropolitan berdampak pada penurunan hasil produksi sawah karena ada petani yang beralih dalam komoditas yang ditanam sejalan dengan adanya perluasan kemitraan dengan pengusaha retail. Jika dibiarkan, hal ini akan memberikan dampak negatif dan mengancam ketahanan pangan kawasan agropolitan Ciwidey sehingga perlu ada intervensi dari pemerintah, organisasi agribisnis, koperasi atau lembaga swadaya masyarakat untuk memberikan pemahaman bagi para petani mengenai agropolitan yang berkelanjutan. 


\section{Evaluasi Implementasi Masterplan Kawasan Agropolitan Ciwidey Menggunakan Logic Models}

\section{Daftar Pustaka}

Departemen Pertanian. (2002). Pedoman umum pengembangan kawasan agropolitan dan pedoman program rintisan kawasan agropolitan. Jakarta: Badan Pengembangan Sumberdaya Manusia Pertanian, Departemen Pertanian.

Farhanah, L., \& Prajanti, S. D. W. (2015). Strategies in developing agropolitan areas in Indonesia. Jurnal Ekonomi Pembangunan, 16(2), 158-165. doi:10.23917/jep.v16i2.1460.

Hoover, E. M. (1977). An introduction to regional economics. New York: Knopf.

Iqbal, M., \& Anugrah, I. S. (2009). Rancang bangun sinergi kebijakan agropolitan dan pengembangan ekonomi lokal menunjang percepatan pembangunan wilayah. Analisis Kebijakan Pertanian, 72), 169-188.

Lo, Fu-Chen, \& Salih, K. (1978). Growth pole strategy and regional development policy. Asian experience and alternative approaches. Nagoya: United Nations Centre for Regional Development.

McLaughlin, J. A., \& Jordan, G. B. (1999). Logic models: A tool for telling your program's performance story. Evaluation and Program Planning, 22, 65-72.

Pemerintah Republik Indonesia. (2012). Peraturan Menteri Pertanian No. 50 Tahun 2012 tentang Pedoman Pengembangan Kawasan Pertanian. Indonesia: Kementerian Pertanian Republik Indonesia.

Poli, A. E., Bisri, M., Surjono, S., \& Lengkong, E. (2013). Agropolitan development in East Tomohon, North Sulawesi Indonesia. IOSR Journal of Business and Management, 13(3), 35-40. doi:10.9790/487X-1333540.

Prasetiya, A., Suyadi, S., Bisri, M., \& Soemarmo. (2014). Analysis of Sendang Agropolitan Area Development, Tulungagung. American Journal of Sociological Research, 4(2), 60-66. doi:10.5923/j.sociology.20140402.06.

Prasetiya, A., Suyadi, S., Bisri, M., \& Soemarmo. (2015). Development strategy of Sendang Agropolitan Area, Tulungagung. International Journal of Applied Sociology, 5(3), 113-120. doi:10.5923/j.ijas.20150503.01.

Rondinelli, D. A. (1985). Applied methods of regional analysis: The spatial dimensions of development policy. Boulder: Westview Press.

Rosdiana, H., \& Murwendah, I. (2014). Evaluation of fiscal policy on agropolitan development to raise sustainable food security (A study case in Bangli Regency, Kuningan Regency and Batu Municipality, Indonesia). Procedia Environmental Sciences, 20, 563-572. doi:10.1016/j.proenv.2014.03.069.

Saefulhakim, S. (2004). Development of agropolitan to promote rural-urban development. Paper presented at Workshop on Agropolitan development as a Strategy for Balanced Rural and Urban Development, Bogor.

Saragih, B. (1998). Kumpulan pemikiran agribisnis: Paradigma baru pembangunan ekonomi berbasis pertanian. Bogor: IPB Press.

Saragih, B. (2007). Refleksi agribisnis. Bogor: IPB Press.

Shaffril, H. A. M., Nasir, A. F. A., Idris, K., Uli, J., \& D’Silva, J. L. (2010). Agriculture project as an economic development tool to boost socio-economic level of the poor community: The case of agropolitan project in Malaysia. African Journal of Business Management, 4(11), 2354-2361.

Soetomo, S. (2002). Dari urbanisasi ke morfologi kota. Mencari konsep pembangunan tata ruang kota yang beragam. Yogyakarta: Graha Ilmu.

Uphoff, N. (1989). Distinguishing power, authority and legitimacy: Taking max weber at his word using resource-exchange analysis. Polity, 22(2), 295-322. doi:10.2307/3234836. 